\title{
The development of holistic face processing: An evaluation with the complete design of the composite task
}

\author{
Paulo Ventura $^{\mathrm{a}, *}$, Isabel Leite ${ }^{\mathrm{b}}$, Tânia Fernandes ${ }^{\mathrm{a}}$ \\ ${ }^{\text {a }}$ CICPSI, Faculdade de Psicologia, Universidade de Lisboa, Alameda da Cidade Universitária, 1649-013 Lisboa, Portugal \\ b Departamento de Psicologia, Universidade de Évora, Apartado 94, 7002-554 Évora, Portugal
}

\section{A R T I C L E I N F O}

\section{Keywords:}

Face processing

Holistic processing

Composite task

Complete design

Partial design

Development of holistic processing of faces

\begin{abstract}
A B S T R A C T
The composite paradigm is widely used to quantify holistic processing (HP) of faces: participants perform a sequential same-different task on one half (e.g., top) of a test-face relative to the corresponding half of a study-face. There is, however, debate regarding the appropriate design in this task. In the partial design, the irrelevant halves (e.g., bottom) of test- and study-faces are always different; an alignment effect indexes HP. In the complete design, besides alignment, congruency between the irrelevant and critical halves of the test-face is manipulated regarding the same/different response status of the study-face. The HP indexed in the complete design does not confound congruency and alignment and has good construct and convergent validities. De Heering, Houthuys, \& Rossion (2007) argued that HP is mature as early as 4-year-olds but employed the partial design. Here we revisit this claim, testing four groups of 4- to 9/10 year-old children and two groups of adults. We found evidence of HP only from 6-year-olds on when considering the complete design, whereas significant alignment effects were found in the index adopted in the partial design already in 4-year-olds but which we demonstrate that reflects other factors besides HP, including response bias associated with congruency.
\end{abstract}

